\title{
ПОСТРОЕНИЕ КОМПЛЕКСНОЙ СИСТЕМЫ РЕГУЛИРОВАНИЯ РЫНКА ЦЕННЫХ БУМАГ В ЕВРОПЕЙСКОМ СОЮЗЕ
}

\author{
(c) 2019 Бутурлин Илья Владимирович \\ Финансовый университет при Правительстве Российской Федерации, Россия, Москва \\ E-mail: buturliniv@gmail.com
}

В статье рассматривается система регулирования рынка ценных бумаг в Европейском Союзе. Предметом исследования являются нормативные акты, регулирующие рынок ценных бумаг, принципы функционирования рынка финансовых инструментов и органы регулирования. В частности, Автор исследует роль Директивы о финансовых инструментах MIFID II в построении единого интегрированного рынка финансовых услуг. Проводит сравнение Директивы ЕС «О рынках финансовых инструментов» с Законом о рынке ценных бумаг РФ. В процессе работы применялся сравнительно-правовой метод исследования, а также анализ, синтез, позволившие сформулировать вывод, что сложилась трехуровневая система регулирования рынка ценных бумаг. Опыт построения комплексной системы регулирования финансовых рынков в Европейском союзе, будет востребован при создании нормативной базы Европейского экономического пространства.

Ключевые слова: финансовое право, публичное право, Европейский союз, предмет, метод, система финансового права, рынок ценных бумаг, общественные отношения, правовые нормы.

В Европейском Союзе сложилась трехуровневая система регулирования рынка ценных бумаг:

- регулирование так называемого первичного законодательства Европейского Союза, а именно Учредительных договоров ЕС, имеющих прямое действие на территории государствчленов ЕС;

- регулирование вторичного законодательства Европейского Союза, то есть нормативных правовых актов (директив и регламентов), которые приняты отдельными институтами управления Европейского Союза в рамках развития положений первичного законодательства (Советом ЕС, Судом ЕС, Комиссией ЕС);

- регулирование национального законодательства государств-членов ЕС.

По сути, европейское законодательство является интеграционным, к нему относятся ранее упомянутые правовые акты первичного и вторичного уровней. И только неурегулированные на указанном уровне вопросы подлежат регулированию национальными законодательствами государств-членов Европейского Союза, как-то максимальные ставки компенсаций рисков финансовой системы для граждан и др.

Что касается правового регулирования рынка ценных бумаг в Европейском Союзе, то отметим, что основной акт первичного законодательства Европейского Союза в сфере экономических взаимоотношений государств-участников ЕС Соглашение о создании Европейского Экономического Сообщества 1957 года со следующими дополнениями и изменениями, включая Лиссабонское Соглашение 2007 года - содержит лишь отсылки о регулировании рынка ценных бумаг, а не прямые положения, что привело к регулированию указанных вопросов на уровне актов институтов Европейского Союза, то есть подавляющее большинство правовых актов интеграционного законодательства о рынке ценных бумаг представляют собой директивы институтов EC.

Основным документом, определявшим систему функционирования рынка ценных бумаг Европейского Союза до 2007 г. выступала Директива Совета Европейского Союза от 10.05.1993 г. № 93/22/ЕЭС «О предоставлении услуг на рынке ценных бумаг» (часто именуют Директивой ISD).

Такое регулирование носило комплексный характер и включало в себя как положение о лицензировании профессиональной деятельности на рынке ценных бумаг, так и положения о контроле такой деятельности и защите прав инвесторов. Директива «ISD» содержала понятия, которые использовались в сфере функционирования рынка ценных бумаг и отображали нужды интеграции. Директива ISD объединила различные регуляторные системы государств-членов EC в единую систему регулирования рынка фи- 
нансовых услуг, в которой были учтены 12 регулятивных подходов - от системы универсальных банков, действующей в ФРГ, до британской системы разделения финансового рынка на сектор коммерческих банков и сектор инвестиционных банков и других инвестиционных посредников. Указанная Директива ISD действовала до вступления в силу в ноябре 2007 г. Директивы Европейского Союза № 2004/39/ЕС от 21.04.2004 г. «О рынках финансовых инструментов» (MiFID).

Директива MiFID закрепляет следующие основные категории рынка ценных бумаг:

- переданные ценные бумаги (англ.«transferable securities»);

- долговые ценные бумаги;

- ценные бумаги, предоставляющие право на приобретение или продажу ценных бумаг.

Законодательство ЕС в сфере рынка ценных бумаг включает: Директиву 98/26/ЕС о законченности расчетов (директива о законченности расчетов) от 19.05.1998 г.; Директиву 2002/47/ EC о финансовом обеспечении (директива о финансовом обеспечении) от 06.06.2002 г.; Директиву 2003/6/ЕС об инсайдерской торговле и рыночных манипуляциях (директива о рыночных злоупотреблениях) от 28.01.2003 г.; Директиву 2003/71/EC о проспектах эмиссии ценных бумаг (директива о проспектах эмиссии - ДПЭ) от 04.11.2003 г.; Директиву 2004/25/ EC о предложениях касательно поглощения (Директива касательно процедуры сообщения о намерении приобрести контрольный пакет акций) от 21.04.2004 г.; Директиву 2004/39/ЕС о рынках финансовых инструментов (директива о рынках финансовых инструментов - ДРФИ) от 21.04.2004 г.; Директиву 2004/109/ЕС о согласовании требований касательно прозрачности информации об эмитентах, чьи ценные бумаги допускаются к продаже на регулированном рынке (Директива о прозрачности - ДП) от 15.12.2007 г.; Директиву 2006/49/ЕС о требованиях касательно достаточности капитала инвестиционных компаний и кредитных учреждений (директива о достаточности капитала - ДДК) от 14.06.2006 г..

Кроме того, 07.11.2006 г. совместными усилиями Федерации европейских фондовых бирж, Европейской ассоциации счетных палат центральных контрагентов и Европейской ассоциации центральных депозитариев ценных бумаг принят «Европейский кодекс поведения при расчетно-клиринговом обслуживании».
Важно подчеркнуть, что финансово-правовое регулирование рынка ценных бумаг в ЕС, а также принципы функционирования рынка финансовых инструментов закреплены следующими директивами.

1. Директива о рыночных злоупотреблениях (директива 2003/6/ ЕС) и ее мероприятия по внедрению были утверждены Европейским парламентом и Советом 23 января 2003 г. и введены в действие с июля 2004 г.

В ней закрепляется цель усилить добропорядочность европейских финансовых рынков путем внедрения общей основы для предотвращения рыночных злоупотреблений и обнаружения таких злоупотреблений, а также для обеспечения поступления на рынок надлежащей информации.

Директива применяется к любому финансовому инструменту, который допускается к обращению (или касательно которого был представлен запрос о допуске к обращению) на регулированном рынке, по крайней мере, в одном государстве-члене ЕС (табл. 2.1) и применяется к любым транзакциям с этими инструментами, независимо от того, где осуществляются такие транзакции - на регулированном рынке или в других местах. Положение об инсайдерских торговых операциях также применяются к деривативам.

Bсе государства-члены ЕС должны применять положение директивы ко всем операциям, которые осуществляются на их территории с финансовыми инструментами, допущенными к обращению на любом регулированном рынке европейской экономической зоны (ЕЭ3) (или касательно которых был представлен запрос о допуске к обращению на таком рынке). Государства-члены также обязаны применять положение этой директивы ко всем операциям, которые осуществляются за границей с финансовыми инструментами, допущенными к обращению на рынке, который находится на их территории (или касательно которых был представлен запрос о допуске к обращению).

Указанная директива о рыночных злоупотреблениях запрещает два распространенных вида рыночных злоупотреблений, а именно: инсайдерскую торговлю и рыночные манипуляции.

Директива запрещает любому, кто владеет инсайдерской информацией, осуществлять (или стараться осуществлять) операции с соответствующими ценными бумагами, поощрять 
других к таким операциям и раскрывать такую информацию. Директива устанавливает три категории инсайдерской информации:

I. Для всех финансовых инструментов, за исключением товарных деривативов, инсайдерская информация определяется как информация о финансовых инструментах, которая является точной, публично не обнародуется и обнародование которой могло бы иметь серьезные последствия для цен на такие инструменты или цен на соответствующие деривативы. Такую информацию взвешенный инвестор мог бы использовать для принятия решений касательно инвестирования.

II. Для товарных деривативов инсайдерская информация определяется как точная, не обнародованная информация, которую участники рынков, у которых такие деривативы находятся в обращении, желали бы получить согласно принятой на таких рынках практике.

III. Для посредников, которые выполняют приказы своих клиентов, инсайдерская информация определяется как точная информация об ожидаемых приказах, обнародование которой могло бы оказать существенное влияние на формирование цен на финансовые инструменты или производные финансовых инструментов.

В Директиве Европейского Парламента и Совета 2003/6/ЕС от 28 января 2003 г. об инсайдерской деятельности и манипуляции на рынке (злоупотреблении на рынке) предусматриваются несколько видов рыночных манипуляций:

I. Манипуляции, связанные с предоставлением транзакциями или приказами о торговле ложных сигналов по спросу и предложению цены, а также случаи, когда цена нарочно устанавливается на ненормальном или искусственном уровне, если только инициатор транзакции не докажет регуляторным органам, что он вел себя таким образом, руководствуясь обоснованными причинами и согласно принятой на рынке практике;

II. Транзакции или приказы о торговле в случае применения тех или других форм мошенничества;

III. Распространение в прессе или по другим информационным каналам, информации, которая предоставляет заведомо ложную информацию о финансовых инструментах, лицами, которые знают или могли бы знать, что такая информация является заведомо ложной.

Директива предусматривает два вида обсто- ятельств, по которым существует «безопасная гавань» - ситуация, которая позволит избежать наказания - торговля собственными акциями в рамках программ обратного выкупа и стабилизация финансового инструмента. Для получения права на приобретение статуса «безопасная гавань», программы обратного выкупа и стабилизационная деятельность должны удовлетворять требованиям, установленным во внедренческих мероприятиях.

В документе предусмотрен механизм повышения качества информации, которая раскрывается участникам рынка:

- обязанность эмитентов предоставлять общественности инсайдерскую информацию;

- обязанность руководства эмитентов акций и тесно связанных с ними лиц раскрывать информацию об операциях с акциями (или другими инструментами, которые имеют отношение к акциям) эмитента;

- обязанность тех, кто проводит исследования, распространяет результаты таких исследований, а равно любую иную информацию, проявлять инициативы в рекомендации или предложении инвестиционных стратегий предоставления достоверной информации и раскрывать информацию о любых интересах или конфликтах интересов;

- обязанность тех, кто осуществляет транзакции сообщать компетентным органам о любых подозрительных транзакциях.

Раскрывая инсайдерскую информацию, эмитенты должны обеспечивать оперативность предоставления информации всем инвесторам одновременно для предотвращения возможности получения некоторыми инвесторами преимущества перед другими инвесторами вследствие быстрого получения информации. Любые существенные изменения в публично обнародованной информации должны также предаваться огласке без каких-либо промедлений. Тем не менее, эмитенты имеют право задерживать раскрытие инсайдерской информации для защиты своих законных интересов, например, во время переговоров, при условии сохранения конфиденциальности информации во время периода задержки с ее раскрытием и, если такая задержка не будет дезориентировать общественность.

Что касается рекомендаций относительно инвестирования, то для обеспечения соблюдения установленных требований государства-члены могут выбирать наиболее прием- 
лемую для них форму регулирования, включая механизмы саморегулирования.

2. Директива о рынках финансовых инструментов была принята Европейским парламентом и Советом в 2004 г. и введена в действие 1 ноября 2007 г. ДРФИ предвещает глубокие трансформации на ландшафте конкуренции ценных бумаг в ЕС. Она открывает банкам возможность действовать в качестве фондовых бирж в некоторых видах деятельности, в качестве альтернативных бирж и предлагать альтернативные услуги, которые являются больше похожими на структуру рынков без посредника, чем на структуру традиционных рынков; директива также открывает возможность децентрализации выполнения доверенностей в широком разнообразии операций, которые раньше регулировались правилами концентрации. Документ предоставляет возможности для организации, функционирования и бизнес стратегий банков, инвестиционных компаний, фондовых бирж, распорядителей активов и других посредников финансовых рынков.

ДРФИ предусматривает два главных приоритета:

1) укрепление единого паспорта для инвестиционных компаний с целью создания возможности предоставления ими инвестиционных услуг в 27 государствах-членах ЕС и трех государствах-участниках европейской экономической зоны на основании одного разрешения и с жестким контролем со стороны государства происхождения. ДРФИ устанавливает надежные правила защиты инвесторов, которые распространяются на весь ЕС. В частности, директива внедряет правила внутреннего управления инвестиционных компаний и согласовывает бизнес-правила торговли ценными бумагами, включая категоризацию клиентов, улучшение проводки операций и отчетность по операциям;

2) отказ от правил концентрации торговли, внедренных Директивой об инвестиционных услугах, что позволит государствам-членам ЕС требовать осуществления торговли ценными бумагами на центральной национальной фондовой бирже или регулированном рынке. Отмена правила концентрации ведет к свободной конкуренции между фондовыми биржами, финансовыми инструментами многосторонней торговли (ФИМТ) и системными интернализаторами торговли финансовыми инструментами, включая оборотные ценные бумаги, инструмен- ты денежного рынка, паи в общем инвестировании, опционы, фьючерсы, свопы и другие деривативы, финансовые контракты на разницу, а также производные инструменты для передачи кредитного риска. Для регулированных рынков, ФИБТ и системных интернализаторов ДРФИ вводит усиленную прозрачность до и после осуществления операций. Тем не менее, указанная прозрачность операций не применяется к рынку облигаций. Это позволяет повысить качество предоставляем услуг, линейку доступных финансовый продуктов и снизить затраты для инвесторов.

Относительно внутреннего управления, ведение бизнеса и отчетности об операциях, то ДРФИ устанавливает для инвестиционных компаний новые требования:

- к внутреннему управлению, которые касаются управления рисками, внутреннего аудита и дисциплины соблюдения законодательства, ограничений на личные операции работников, менеджеров и директоров, ограничений на аутсорсинг третьим странам, а также общей политики выявления, урегулирования конфликтов интересов и раскрытия информации о них;

- к ведению бизнеса, относящиеся к способности инвестора, с учетом его опыта, склонности к риску и инвестиционным целям, осуществлять инвестиционную деятельность и управлять инвестиционным портфелем, а также приемлемости других услуг, т.е. инвестор должен понимать риск, за исключением ограниченного класса несложных продуктов. Последние известны как правила «знай своих клиентов». Выполняя доверенности своих клиентов, инвестиционные компании также должны демонстрировать лучшее мастерство выполнения. В частности, они должны совершать действия, направленные на получение лучших результатов для своих клиентов с учетом цены, расходов, скорости, возможности выполнения и расчетов, размера и любых других соответствующих факторов. ДРФИ также требует от инвестиционных компаний принять политику выполнения доверенностей и получить предварительное соглашение клиентов на такую политику. Такое предварительное соглашение является обязательным в случаях, когда политика позволяет выполнять доверенность за пределами регулированных рынков или ФИБТ. Компании должны осуществлять мониторинг эффективности своей политики, исправлять недостатки и доказывать, по запросам клиентов, 
что компания придерживается определенной политики. Платежи, которые делаются компаниям в связи с предоставлением инвестиционных услуг, должны быть обоснованными и полностью доводиться до сведения клиентов, а также повышать качество услуг, которые предоставляются клиентам. В случае розничных клиентов ДРФИ требует обязательно заключать с ними письменное соглашение.

Требования к отчетности об операциях касаются отчетности перед регуляторными органами по операциям купли/продажи всех финансовых инструментов, которые допускаются к обращению на регулированном рынке, и обмене информацией между компетентными органами для обеспечения надлежащего надзора. Из обязательств по операциям на первичном рынке, финансировании ценных бумаг и исполнении опционов существуют исключения. В случае с процентными, валютными и товарными деривативами фондовая биржа отчитывается местным регуляторным органам об операциях, поскольку в таких случаях торговля допущенными к обращению инструментами осуществляется при участии посредника. Некоторые регуляторные органы применяют эти правила к более широкому кругу инструментов, например, лишь к инструментам, которые продаются без посредника и которые не допущены к обращению на регулированном рынке.

ДРФИ устанавливает детальные требования к организации деятельности и операций регулированных рынков и ФИБТ, а также предусматривает детальные положения касательно прозрачности, которые применяются к допущенным к обращению на регулированных рынках финансовых инструментов, ФИБТ и системных интернализаторов. Тем не менее положения ДРФИ относительно прозрачности не применяются к рынкам облигаций.

ДРФИ вводит детальные требования относительно полного раскрытия информации о ликвидных акциях до заключения соглашения. Эти требования касаются опубликования системными интернализаторами цен предложений, а также лимитных указаний клиентов и дальнейшего их выполнения. ДРФИ также устанавливает требования касательно полного раскрытия информации о всех зарегистрированных акциях и их деривативах после заключения соглашения. Требования распространяются на отчетность об: операциях в реальном времени; соглашени- ях между сторонами об ответственности за публикации информации; возможности задержки опубликования информации в случаях больших операций; публикации операций, которые осуществляются без посредника и в нерабочее время.

В Европейском Союзе полномочия по регулированию рынка ценных бумаг в наднациональном масштабе осуществляют согласованно:

- профильные комитеты при Совете ЕС по экономике и социальным вопросам

- Комитет по европейским ценным бумагам, на который Решением Комиссии ЕС от 06.06.2001 № 2001/528/Е возложена координация деятельности ЕС в сфере регулирования рынка ценных бумаг. Кроме того, ст.2 упомянутого Решения устанавливает в качестве одной из основных задач Комитета формирование рекомендаций Комиссии ЕС в области политики на рынке ценных бумаг.

В это же время, Решением Комиссии ЕС (от 6 июня 2001 г. № 2001/527/ЕС) создается независимая консультативная группа, цель которой состоит в проведении срочных консультаций по вопросам функционирования рынка ценных бумаг - «Комитет регуляторов рынка ценных бумаг EC» (ст. 2).

Также, в сфере регулирования рынка ценных бумаг, существуют органы наднационального характера (в частности «IOSCO12», объединяющее около 90\% мирового рынка ценных бумаг более 100 государств мира), которые не являются регуляторами в полном понимании этого слова.

На сегодняшний день в ЕС не существует единого органа регулирования рынка ценных бумаг, который был бы полноценно наделен функциями контроля и надзора. Оговоримся, что создание аналога Европейского Центрального Банка для регулирования рынка ценных бумаг и финансовых услуг, не связанных с банковским сектором, не является обязательным и необходимым.

Как отмечает И.М. Лифшиц, упомянутые Директивы устанавливают лишь необходимые требования, но окончательного ответа о конфигурации национальных регуляторов ценных бумаг, их функциях и полномочиях не содержат.

Национальные законодательства большинства европейских государств самостоятельно определяют порядок функционирования регуляторов рынка ценных бумаг внутри Европей- 
ского Союза. Оговоримся, что входящие в Европейский Союз государства применяют разные модели регулирования рынка ценных бумаг (что уже ранее отмечалось) - от создания мегарегулятора на всем финансовом рынке до использования различных узко направленных органов на каждом самостоятельном направлении рынка ценных бумаг.

Проведем сравнительное исследование основного общего документа Европейского Союза о регулировании рынка ценных бумаг - Директивы «О рынках финансовых инструментов» от 21.04.2004 № 2004/39/ЕС - и отечественного Закона «О рынке ценных бумаг».

Оба данных документа, хоть и имеют ряд общих черт, и в первую очередь - объект регулирования, однако, отличаются как по структуре, так и по содержанию. В частности: Директива ЕС от 21 апреля 2004 г. «О рынках финансовых инструментов» (MiFID) содержит 5 разделов, 6 глав, 3 секции и 73 статьи, в то же время, Закон о рынке ценных бумаг - 6 разделов, 13 глав и 53 статьи.

При этом, если первые и последние разделы данных нормативных актов (Общие и заключительные положения) сходны, то в остальных имеется и ряд существенных содержательных различий.

Taк, MiFID огромное значение придает защите инвесторов - участников рынка, в то время как Закон эти вопросы практически не регламентирует, в то же время, большое внимание уделяется видам участников рынка ценных бумаг, эмиссионным ценным бумагам и раскрытию информации.

Сравнительно недавно, 3 января 2018 г. вступили в законную силу и начали свое действие Директива ЕC «О рынках финансовых инструментов» (Markets in Financial Instruments Directive - MiFID II) и Регламент EC «O рынках финансовых инструментов» (Markets in Financial Instruments Regulation - MiFIR). Как отмечает P.А. Касьянов, основной целью проводимых реформ в правовом регулировании рынка ценных бумаг в Европейском Союзе является попытка построения единого европейского интегрированного рынка финансовых услуг.

Европейская правовая наука рассматривает указанные правовые акты интеграционного законодательства о рынке ценных бумаг как «спинной хребет финансового регулирования», можно сказать, «скелет», который впоследствии должен «обрасти» полным массивом актов пра- вового регулирования отношений в данной сфере. Как заявил действующий в тот момент еврокомиссар по вопросам внутреннего рынка и услуг М. Барнье в своем интервью в январе 2014, Европейский Союз и органы управления могут исключительно приветствовать достигнутое между Европейским парламентом и Советом по пересмотру правил, регулирующих рынки финансовых инструментов принципиальное соглашение, а установленные соглашением правила будут способствовать улучшению качества функционирования рынков капитала в интересах реального сектора экономики.

Необходимо отметить, что в Европейском Союзе сложилась трехуровневая система регулирования рынка ценных бумаг. Основу ее составляют Директивы ЕС, основной из них является Директива Европейского Союза «О рынках финансовых инструментов» от 21.04.2004 № 2004/39/EC, регулирующая вопросы, аналогичные регулируемым Федеральным Законом «О рынке ценных бумаг», что подтверждают результаты приведенного выше сравнительного анализа названных правовых актов.

Несомненно, накопленный Европейским Союзом опыт регулирования финансовых рынков найдет свое применение в процессе создания системы нормативного правового регулирования Европейского экономического пространства.

Как указывает М.А. Эскиндаров, сложный процесс гармонизации правовых систем государств, входящих в Единое экономическое пространство, в том числе в части правового регулирования рынка финансовых инструментов и ценных бумаг не должен оставить несправедливо забытым существующий опыт Европейского Союза и лучшую мировую практику. Это, прежде всего, должно выражаться в учете и использовании документов Совета по финансовой стабильности, Международного валютного фонда, Всемирного Банка, Комитета по банковскому надзору и других институтов Европейского Союза и международных организаций по вопросам, касающимся экономической и финансовой интеграции.

Указанные обстоятельства обусловливают необходимость и значимость анализа Директив и Регламентов Европейского Союза в области финансовых рынков, в том числе рынка ценных бумаг. Особый интерес должны представлять Директива ЕС о листинге, Директива ЕС о рын- 
ках ценных бумаг, Директива ЕС об инвестиционных фондах и Директива ЕС о достаточности капитала финансовых учреждений.

Не следует при этом ограничиваться опытом нормативно-правового регулирования рынка ценных бумаг. Представляется весьма перспективным и использование европейского опыта функционирования транснациональных регулятивных органов в данной области, как-то: Европейское банковское агентство. Европейский совет по системному риску, Европейское агентство по фондовому рынку и др. При этом оговоримся, что различия в национальном правовом регулировании финансовых рынков не могут и не должны препятствовать функционированию объединенного европейского рынка, если они имеют стилистический или иной несущественных характер (например, существуют различия в определении видов банка или в понимании различных видов ценных бумаг).
Ученые отмечают, что сравнение объема различий в законодательстве государств-членов ЕС при создании единого финансового рынка и законодательства государств, входящих в Единое экономическое пространство, отнюдь не в пользу Европейского Союза. Однако данное обстоятельство не стало препятствием для успешного решения вопросов правового регулирования и функционирования единого финансового рынка в Евросоюзе.

Учитывая интеграционные процессы, проходящие на международных финансовых рынках, Российской Федерации необходимо использовать опыт Европейского союза и предпринять шаги по реформированию законодательства в целях создания более эффективного механизма привлечения капитала в реальный сектор экономики и создания надежной системы защиты прав инвесторов в рамках Единого Экономического Пространства.

\section{Библиографический список}

1. Иншакова А.О. Унификация корпоративного регулирования в Европейском Союзе и Содружестве Независимых Государств: Автореферат диссертации на соискание ученой степени доктора юридических наук.М., 2008. С. 16-17.

2. Договор об учреждении Европейского экономического сообщества. [Электронный pecypc]. URL: http://www. conventions.ru/view_base.php?id=1537

3. Директива Совета 93/22/ЕЕС от 10 мая 1993 г. о предоставлении услуг на рынке ценных бумаг // СИ. 1993.

4. Директива Европейского Парламента и Совета 2004/39/EC от 21 апреля 2004 г. о рынках финансовых инструментов, о внесении изменений в Директиву 2001/34/EC // ОJ.2004. L 145.

5. Административное право зарубежных стран: Учебник / Под ред. А.Н. Козырина и М.А. Шатиной.- М., 2003. C. $4-5$.

6. Директива Европейского Парламента и Совета 98/26/ЕС об законченности расчетов в платежных системах и системах расчетов по ценным бумагам // 01. 1998. L 166.

7. Директива Европейского Парламента и Совета 2002/47/ЕС от 6 июня 2002 г. о соглашении в отношении финансового обеспечения // 01. 2002. L 168.

8. Директива Европейского Парламента и Совета 2003/6/ЕС от 28 января 2003 г. об инсайдерской деятельности и манипуляции на рынке (злоупотреблении на рынке) // OJ. 2003. L 96.

9. Директива Европейского Парламента и Совета Европейского Союза 2003/71/ЕС от 4 ноября 2003 г. о публикации проспекта при размещении ценных бумаг среди публичных инвесторов или при допуске ценных бумаг к торгам и об изменении Директивы 2001/34/EC // 12.2003 ОЈ. 345.

10. Директива Европейского Парламента и Совета 2004/25/ЕС от 21 апреля 2004 г. о предложениях о поглощении // ОJ. 2004. L 142.

11. Директива Европейского Парламента и Совета 2004/39/EС от 21 апреля 2004 г. о рынках финансовых инструментов, о внесении изменений в Директиву 2001/34/EC // ОJ. 2004. L 145.

12. Директива 2004/109/ЕС о согласовании требований касательно прозрачности информации об эмитентов, чьи ценные бумаги допускаются к продаже на регулированном рынке // OJ. 2004. L 390/38.

13. Директива Европейского Парламента и Совета 2006/49/ЕС от 14 июня 2006 г. о достаточности капитала инвестиционных компаний и кредитных учреждений // OJ. 2006. L 177.

14. Зеккер Ф.Ю. Основы единообразного толкования права Европейского Союза // Проблемы гражданского и предпринимательского права Германии. - М., БЕК, 2001. С. 28-31.

15. Директива Европейского Парламента и Совета 2004/39/ЕС от 21 апреля 2004 г. о рынках финансовых инструментов, о внесении изменений в Директиву 2001/34/EC // ОJ.2004. L 145. 
16. Решение Комиссии 2001/528/ЕС от 6 июня 2001 г. об учреждении Европейского комитета по ценным бумагам // OJ. 2001. L 191.

17. Решение Комиссии 2001/527/ЕС от 6 июня 2001 г. об учреждении Комитета Европейских фондовых регуляторов // OJ. 2001. L 191.

18. Лифшиц И. М. Правовое регулирование рынка ценных бумаг в Европейском союзе.- М.: Статут, $2012 .-253$ c.

19. Касьянов P.A. MIFID II и Россия: Сопоставимо ли регулирование// Законы России: опыт, анализ, практика. 2018. № 5. C. 86-91.

20. Thierry BONNEAU, MIF II: aperçu général de la directive et du règlement du 15 mai 2014// Revue de Droit bancaire et financier $n^{\circ}$ 6, Novembre 2014, dossier 59. Available at: https://ebi-europa.eu/wp-content/uploads/2016/12/ Travaux.pdf (accessed: 25.03.2018)

21. European Commission, Press Release «Markets in Financial Instruments (MiFID): Commissioner Michel Barnier welcomes agreement in trilogue on revised European rules» (Brussels, 14 January 2014) // MEMO/14/15. Available at: http://europa.eu/rapid/press-release_MEMO-14-15_en.htm?locale=en (accessed: 25.03.2018)

22. Эскиндаров М.А. Проблемы интеграции Финансовых рынков стран Единого Экономического Пространства // Вестник Финансового университета. 2014. № 1 (79). С. 8-19. 